\title{
Internet Addiction and Estimation Procedure, Among Computer and Medical Professional Students: A Cross Sectional Study Odisha, India
}

\author{
Bulu Mahanty ${ }^{1, *}$, Gopabandhu Mishra ${ }^{2}$ \\ ${ }^{1}$ Department of Community Medicine, Hi-tech Medical College \& Hospital, Bhubaneswar, Odisha, India \\ ${ }^{2}$ P. G. Department of Statistics, Utkal University Vanivihar, Bhubaneswar, Odisha, India
}

\author{
Email address: \\ bulu.mahanty@gmail.com (B. Mahanty) \\ ${ }^{*}$ Corresponding author
}

\section{To cite this article:}

Bulu Mahanty, Gopabandhu Mishra. Internet Addiction and Estimation Procedure, Among Computer and Medical Professional Students: A Cross Sectional Study Odisha, India. International Journal of Biomedical Materials Research. Vol. 4, No. 1, 2016, pp. 1-5. doi: 10.11648/j.ijbmr.20160401.11

Received: April 14, 2016; Accepted: May 6, 2016; Published: August 17, 2016

\begin{abstract}
This paper is about the Estimation of internet addiction of MCA Students \& Medical Students of Hi-tech medical college \& hospital at Utkal University, Bhubaneswar, Odisha. It has transformed academic landscape Research over the last decade has identified Internet addiction as a new and often unrecognized clinical disorder that impact a user's ability to control online use to the extent that it can cause relational, occupational, and social problems. A total of 100 study participants were selected. Probability sampling technique of cluster sample of two cluster \&a cross-sectional study of the students of Master in computer Application 50 Students \& Hi-tech medical college \& hospital 50 students were scored using a questionnaire to determine the number of hours they spend on the use of internet and also the purpose for which they use internet $\&$ its risk factors, estimation of future trends. From the result most of them are internet addicted $69.61 \%$ are mild addiction but most of MCA students are severe (75 out of 100 scores) addicted but most of Medical Students are mild addicted (63 out of 100 scores). Higher the score range the greater the level of internet addiction, risk factors are higher. Further it was observe through the advance statistical analysis pair $t$ test for impact of internet addiction \& Estimation procedure apply by linear Regression analysis for predict the future internet addiction show that a significant among MCA \& Medical Students for internet addiction $\&$ are having high risk factors for health, family, friends, psychological, angry etc. have positive impact. The study showed that more than $70 \%$ of students are mild addiction out of which MCA students are severe risk than the medical students. For $47 \%$ of the students reason for surfing is nonacademic work i.e. personal out of which $9 \%$ are others like Porn \& Online Purchasing, Online movies, etc. Thus it is essential to orient the students on using internet for their studies for better career and life.
\end{abstract}

Keywords: Internet Addiction, Risk Factor, Paired t Test, Linear Regression, SPSS 22.0

\section{Introduction}

Internet use: In the section on Internet use, adolescents were asked to state how frequently and where they used the Internet and whether they are supervised when using it. In addition to this, the following Internet application uses were inquired about in terms of days per week and hours per day: instant messenger (e.g., MSN), e-mail, surfing, Twitter, chat, social networking sites (e.g., Face book), forums, Hotel, weblogs, YouTube, online poker, downloading, television and radio, Songs (audio\& video),
Porn site, Movies etc...Live streaming, as well as online, offline, and browser games. For these variables, usage hours per week were calculated in order to provide a more detailed and elaborated picture of overall usage.

What is Internet addiction?

1. Internet addiction is described as an impulse control disorder, which does not involve use of an intoxicating drug and is very similar to pathological gambling.

2. Internet addiction is described as an impulse control disorder, which does not involve use of an intoxicating drug and is very similar to pathological gambling. 
3. While time spent online can be hugely productive, compulsive Internet use can interfere with daily life, work, and relationships. When you feel more comfortable with your online friends than your real ones, or you can't stop yourself from playing games, gambling, or compulsively checking your smartphone, tablet, or other mobile device-even when it has negative consequences in your life - then you may be using the Internet too much.

What are the effects?

Internet addiction results in personal, family, academic, financial, and occupational problems that are characteristic of other addictions. Impairments of real life relationships are disrupted as a result of excessive use of the Internet. Which results in distrust and the disturbance of quality in once stable relationships?

Those who are at highest risk for creating a secret life are those who suffer from low-self-esteem, feelings of inadequacy, and fear of disapproval are negative self-concepts that lead to clinical problems of depression and anxiety.

Anger, depression, relief, mood swings, anxiety, fear, irritability, sadness, loneliness, boredom, restlessness, procrastination, and upset stomach. Being addicted to the Internet can also cause physical discomfort or medical problems such as: Carpal Tunnel Syndrome, dry eyes, backaches, severe headaches, eating irregularities, (such as skipping meals), failure to attend to personal hygiene, and sleep disturbance. [3]

Internet addiction and pornography

Young (1999), a founding member of the centre for OnLine Addiction claims Internet addiction is a broad term that covers a wide variety of behaviors and impulse control problems [4, 5]. She claims this is categorized by five specific subtypes including:

1. Cybersexual addiction: compulsive use of adult websites for cybersex and cyber porn.

2. Cyber-relationship addiction: Over-involvement in online relationships.

3. Net compulsions: Obsessive online gambling, shopping or day-trading.

4. Information overload: Compulsive web surfing or database searches.

5. Computer addiction: Obsessive computer game playing. [3]

Problematic and Risky Internet Use Scale (PRIUSS)

A newer 18-item measure is the PRIUSS, the Problematic and Risky Internet Use Screening Scale, has been developed by Jelenchick and colleagues in 2012 at the University of Wisconsin School Of Medicine. This scale differed in that it was based on a conceptual model of PIU created in an earlier study [1] and has been validated through factor analysis during its development. [2] The instrument is currently being launched in several schools and clinics, as well as being evaluated through further research; it contains 18 items.

Risk

In this context, the definition for Internet addiction risk was defined as the probability of addiction for a person possessing a particular personality trait and/or using a specific application of the Internet relative to a person who does not have the trait and/or does not use the specific application. In contrast to that, a risk ratio refers to the event of addiction relative to the risk of addiction, and can therefore reach a maximum of 1 (Sistrom \& Garvan, 2004).

The internet offers two main benefits: communication and information [11]. Internet usage has the potential to improve the quality of education. It has been reported that computerbased learning can increase understanding of theoretical and critical concepts [12]. The popularity of the Internet as a teaching-learning tool increased with the introduction of the web browser, which uses a hypertext concept [13]. With text and graphical images, and later video, audio, and animated objects, it became easily distributed over the Internet. The value of the Internet for educational purposes is enhanced as it brings about positive changes to teachers and instructors, who taught students to learn, work, communicate, and play [14].

\section{Material and Methods}

The study was a cross sectional study. It was conducted among MCA Computer professional\& Medical Students in Utkal University randomly. The period of study was Nov.2015 to January 2016. A Model Questionnaire was used to as the tool to gather the information and data for the study. Data analysis was done by using the statistical software statistical package for service solution (SPSS 22.0). Descriptive statistics \& frequency distribution of the study sample \& its comparison between the two institutions.

Out of 100 study participants 50:50 from each cluster MCA \&Medical. All the students age group 21 to $24 \&$ from medical students are age group 20 to 25 , Gender wise MCA \& Medical Male $32 \& 35$ and Female 18 \& 15, Marks obtain from before internet uses \& its addicted Mean \pm SD (68.68 \pm 10.46$)$ (69.24 \pm 6.81$)$, Marks obtain from after internet uses \& its addiction Mean \pm SD (60.80 \pm 7.56$)(64.52 \pm 7.37)$, and Monthly income of the family per month of MCA\& Medical is Mean $\pm \mathrm{SD}(24.78 \pm 9.55,58.92 \pm 20.95)$. All the students had their own computer with either Wi-Fi connection or Cable, dongle internet network.

Table 1. Distribution of Students.

\begin{tabular}{|c|c|c|c|}
\hline \multicolumn{4}{|c|}{ SEX wise distribution of study Cluster sample } \\
\hline \multirow{2}{*}{ PROFESSIONAL } & \multicolumn{3}{|c|}{ SEX } \\
\hline & MALE & FEMALE & TOTAL \\
\hline MCA & 32 & 18 & 50 \\
\hline MEDICAL & 35 & 15 & 50 \\
\hline TOTAL & 67 & 33 & 100 \\
\hline
\end{tabular}

Table 2. AGE \& Sex Wise Distribution.

\begin{tabular}{llll}
\hline \multirow{2}{*}{ AGE } & \multicolumn{3}{l}{ SEX } \\
& MALE & FEMALE & TOTAL \\
\hline BELOW 20 & 2 & 0 & 2 \\
$20-22$ & 10 & 1 & 11 \\
$22-24$ & 44 & 27 & 71 \\
ABOVE 24 & 11 & 5 & 16 \\
TOAL & 67 & 33 & 100 \\
\hline
\end{tabular}


From the data above table 1 distribution of students shows that the majority of the students were from Male $67 \%$ and $33 \%$ female out of 100 samples. The table 2 gives the age \& sex wise distribution of study sample gives maximum subject are from age group 22 to 24 both male \& female and minimum numbers are from below 20 age group but not a single sample from female age group below 20 .

Table 3. Distribution of Internet Use \& Its Purpose.

\begin{tabular}{lllll}
\hline PURPOSE & & & & \\
\hline STUDENT_GROUP & Frequency & Percent & $\begin{array}{l}\text { Cumulative } \\
\text { Percent }\end{array}$ \\
\hline \multirow{4}{*}{ MCA } & PROFESSIONAL & 23 & 46 & 46 \\
& PERSONAL & 21 & 42 & 88 \\
& OTHERS & 6 & 12 & 100 \\
& Total & 50 & 100 & \\
\multirow{4}{*}{ MEDICAL } & PROFESSIONAL & 21 & 42 & 42 \\
& PERSONAL & 26 & 52 & 94 \\
& OTHERS & 3 & 6 & 100 \\
\hline
\end{tabular}

From the above table 3 gives the purpose of MCA student's gives the maximum were professional 23 (46\%) but in case of medical students they use for the personal 26 $(52 \%)$ purpose. out of 100 number of sample.
Table 4. Most of the Site Visit.

\begin{tabular}{|c|c|c|c|c|}
\hline \multicolumn{5}{|c|}{ SITEVISITMOST } \\
\hline STUDENT & GROUP & Frequency & Percent & Cumulative Percent \\
\hline \multirow{5}{*}{ MCA } & $\begin{array}{l}\text { SUBJECT } \\
\text { RELATED }\end{array}$ & 19 & 38 & 38 \\
\hline & $\begin{array}{l}\text { SOCIAL } \\
\text { NETWORK }\end{array}$ & 16 & 32 & 70 \\
\hline & GAMES & 9 & 18 & 88 \\
\hline & OTHERS & 6 & 12 & 100 \\
\hline & Total & 50 & 100 & \\
\hline \multirow{5}{*}{ MEDICAL } & $\begin{array}{l}\text { SUBJECT } \\
\text { RELATED }\end{array}$ & 14 & 28 & 28 \\
\hline & $\begin{array}{l}\text { SOCIAL } \\
\text { NETWORK }\end{array}$ & 24 & 48 & 76 \\
\hline & GAMES & 9 & 18 & 94 \\
\hline & OTHERS & 3 & 6 & 100 \\
\hline & Total & 50 & 100 & \\
\hline
\end{tabular}

From the above table 4 title as Most of the Site Visit gives, Maximum MCA students were subject related 19 (38\%) followed by social network $16(32 \%)$. But in case of Medical students they use internet for the Social Network 24 (48\%). Out of 100 number of sample.

Table 5. Descriptive statistics.

\begin{tabular}{|c|c|c|c|c|c|c|}
\hline \multicolumn{2}{|c|}{ STUDENT_GROUP } & \multirow{2}{*}{$\frac{\mathbf{N}}{50}$} & \multirow{2}{*}{$\frac{\text { Minimum }}{12.00}$} & \multirow{2}{*}{$\begin{array}{l}\text { Maximum } \\
60.00\end{array}$} & \multirow{2}{*}{$\frac{\text { Mean }}{24.7800}$} & \multirow{2}{*}{$\frac{\text { Std. Deviation }}{9.55818}$} \\
\hline & INCOME_FAMILY & & & & & \\
\hline & HOURSOFINTERNETUSE PER DAY & 50 & 2.00 & 6.00 & 4.3200 & 1.34680 \\
\hline & HOURSPERWEEK & 50 & 14.00 & 42.00 & 30.2400 & 9.42762 \\
\hline & IMAPCT_FRND & 50 & 1.00 & 4.00 & 1.5200 & .70682 \\
\hline \multirow[t]{8}{*}{ MCA } & IMPACT_STUDY & 50 & 1.00 & 5.00 & 4.1200 & 1.09991 \\
\hline & IMPACT_FAMILY & 50 & 1.00 & 5.00 & 2.5600 & 1.23156 \\
\hline & IMPACT_HEALTH & 50 & 1.00 & 5.00 & 4.1200 & 1.11831 \\
\hline & PAYFORINTERNET & 50 & 1.00 & 2.00 & 1.7800 & .41845 \\
\hline & Valid N (list wise) & 50 & & & & \\
\hline & INCOME_FAMILY & 50 & 30.00 & 125.00 & 59.8200 & 20.95251 \\
\hline & HOURSOFINTERNETUSE PER DAY & 50 & 1.00 & 6.00 & 3.1400 & 1.44293 \\
\hline & IMAPCT_FRND & 50 & 1.00 & 4.00 & 1.4000 & .78246 \\
\hline \multirow[t]{5}{*}{ MEDICAL } & IMPACT_STUDY & 50 & 1.00 & 5.00 & 4.3000 & .97416 \\
\hline & IMPACT_FAMILY & 50 & 1.00 & 5.00 & 1.9400 & 1.18511 \\
\hline & IMPACT_HEALTH & 50 & 1.00 & 5.00 & 3.9400 & 1.20221 \\
\hline & PAYFORINTERNET & 50 & 1.00 & 2.00 & 1.1400 & .35051 \\
\hline & Valid N (list wise) & 50 & & & & \\
\hline
\end{tabular}

From the above table 5 gives the Descriptive Statistics of MCA students gives the average income of the family Rs. 24,780 with a S. D. of 9.55 but in medical students average income of the family Rs. 59.820 with S. D. 20.95 .

MCA students gives the average HOURS OF INTERNET USE4.3 Hours with a S. D. of 1.34 but in medical students average HOURS OF INTERNET USE 3.14 with S. D. 1.44 .

MCA students give the average HOURSPERWEEK 30.24
Hours with a S.D. of 9.55 but in medical students average HOURSPERWEEK 21.98 with S.D. 10.10.

MCA students gives the average \& S. D. Impact of friends, study, family \& health $1.52 \pm .70,4.12 \pm 1.09,2.56 \pm 1.23$, $4.1 \pm 1.11$ but in medical students average $1.40 \pm .78,4.3 \pm .97$, $1.94 \pm 1.18,3.94 \pm 1.20$, out of 100 sample.

MCA students give the average PAY FOR INTERNET Rs 178.00 with a S. D. of Rs.0.41 but in medical students average PAY FOR INTERNET 1.14 with S.D. 0.35. 
Table 6. Paired Samples Test.

\begin{tabular}{|c|c|c|c|c|c|c|c|c|c|}
\hline \multirow{3}{*}{\multicolumn{2}{|c|}{ STUDENT_GROUP }} & \multicolumn{5}{|c|}{ Paired Differences } & \multirow{3}{*}{$t$} & \multirow{3}{*}{ df } & \multirow{3}{*}{ Sig. (2-tailed) } \\
\hline & & \multirow{2}{*}{ Mean } & \multirow{2}{*}{ S.D. } & \multirow{2}{*}{ SE mean } & \multicolumn{2}{|c|}{$\begin{array}{l}95 \% \text { Confidence Interval } \\
\text { of the Difference }\end{array}$} & & & \\
\hline & & & & & Lower & Upper & & & \\
\hline MCA & BEFORE_INT - AFTER_INT & 7.88 & 12.67 & 1.79 & 4.27 & 11.48 & 4.39 & 49 & .001 \\
\hline MEDICAL & BEFORE INT - AFTER INT & 4.72 & 9.169 & 1.29 & 2.11 & 7.326 & 3.64 & 49 & .001 \\
\hline
\end{tabular}

Table 7. Analysis Of Variance.

\begin{tabular}{lllllll}
\hline ANOVA $^{\text {a }}$ & & & & & \\
\hline Model & Sum of Squares & df & Mean Square & F & Sig. \\
\hline & Regression & 3879.547 & 2 & 1939.774 & 13.581 & .001 \\
1 & Residual & 13854.243 & 97 & 142.827 & & \\
& Total & 17733.790 & 99 & & & \\
\hline
\end{tabular}

a. Dependent Variable: INTERNET_ADDICTION

b. Predictors: (Constant), INCOME_FAMILY, HOURSPERWEEK

From the above table 6 gives the results of paired $t$ statistics of 4.39 with 49 degrees of freedom. The two tailed $p$ value is 0.001 , which is less than the conventional 5\% level of significance. That means the average output of the Internet addiction has indeed changed after professional course. out of 50 MCA students.

The results of Paired $t$ statistics of 3.64 with 49 degrees of freedom. The two tailed $p$ value is 0.001 , which is less than the conventional $5 \%$ level of significance. That means the average output of the Internet addiction has indeed changed after professional course. Out of 50 medical students.

From the above table 7 titled as ANOVA gives the Fstatistic the $p$-value associated with it. The F-statistic is the Mean Square (Regression) divided by the Mean Square (Residual): $2385.93 / 51.096=46.695$. The $p$-value is 0.001 alpha levels in testing the null hypothesis that all of the model coefficients are 0 .

Table 8. Coefficients.

\begin{tabular}{|c|c|c|c|c|c|c|}
\hline \multicolumn{7}{|c|}{ Coefficientsa } \\
\hline \multirow{2}{*}{\multicolumn{2}{|c|}{ Model }} & \multicolumn{2}{|c|}{ Unstandardized Coefficients } & \multirow{2}{*}{$\begin{array}{l}\text { Standardized Coefficients } \\
\text { Beta }\end{array}$} & \multirow{2}{*}{ t } & \multirow{2}{*}{ Sig. } \\
\hline & & B & Std. Error & & & \\
\hline \multirow{3}{*}{1} & (Constant) & 74.061 & 4.377 & & 16.920 & .001 \\
\hline & HOURSPERWEEK & .195 & .118 & .154 & 1.661 & .100 \\
\hline & INCOME OF FAMILY & -.226 & .052 & -.404 & -4.346 & .001 \\
\hline
\end{tabular}

a. Dependent Variable: INTERNET_ADDICTION

These are the values for the regression equation for predicting the dependent variable from the independent variable. The regression equation is presented in many different ways, for example:

$$
\begin{aligned}
(\text { Internet Addiction })= & 74.06+.195(\text { Hours per week })+- \\
& .226(\text { income of family })
\end{aligned}
$$

The column of estimates provides the values for Constant, Hours per week, and Income of Family for this equation.

\section{Summery \& Conclusion}

The study showed that more than $70 \%$ of students are Mild addiction out of which MCA students are Severe Risk than the medical students.

Out of 100 study participants 50:50 from each Cluster MCA \& Medical Students. All the students age group 20 to 25 i.e. younger age groups, More Male students are internet addicted than female students, because of internet addiction Average Marks obtained from before internet uses was good than after use of internet that's may be the cause of internet addiction, Monthly income of the family Medical students have more than the MCA students. All the students had their own computer with either Wi-Fi connection or Cable, dongle internet network.
From the above result we conclude that MCA students are Internet addicted Severe because they are the computer professional but MCA students must take precaution for their health and academic.

From the above result we conclude that MEDICAL students are Internet addicted MILD Than MCA students because there family income is higher than the MCA students, so MEDICAL students also take precaution for their health and academic.

Our results indicate that majority of the MCA students spend average 4.30 Hours internet use per day but in medical students 3.14 hours internet use per day. Only use internet for pure academic work which can help them to understand the subject and help to improve the knowledge, academic performance.

This can be managed by their institutes through Counseling, Seminar and Workshops. Students should be suggested to browse specific sites related to their subject and which can be followed by a group discussion in their class which can be beneficial to all the students.

Parents can also offer guidance to students to focus and understand priorities while studying. In this era of rapid expansion of IT students should use internet as the advantage for knowledge improvement. They should learn to balance between social and academic use. This will help them to improve subject knowledge and quality of their work. 


\section{References}

[1] Moreno MA, Jelenchick LA, Christakis DA (2013). "Problematic internet use among older adolescents: A conceptual framework". Computers and Human Behavior 29: 1879-1887.

[2] Lauren Jelenchick. "The problematic \& Risky Internet Use Screening Scale (PRIUSS) for Adolescents and Young Adults; Intial Scale Development and Refinement" (PDF). Retrieved 14 March 2014.

[3] https://en.wikipedia.org/wiki/Internet_addiction_disorder.

[4] Young, K. (1999). The research and controversy surrounding internet addiction. CyberPsychology and Behavior, 2, 381383. Springer Int J Ment Health Addict (2006) 51.

[5] Young, K. (1999b). Internet addiction: Symptoms, evaluation and treatment. In L. Vande Creek \& T. Jackson (Eds.), Innovations in clinical practice: A source book, 17 (pp. 1931). Sarasota, Florida: Professional Resource Press.

[6] Rewati Limaye, Prof. Dr. Gerhard Fotwengel (2015). Use of Internet Among Undergraduate Students From Mumbai, India, ISSN: 2230-7109 (Online) | ISSN: 2230-9543 (Print), IJECT Vol. 6, Issue 2, April - June 2015.

[7] Kandell, J. J. (1998). Internet addiction on campus: The

vulnerability of college students. Cyber Psychology and Behavior. 1 (1), 11-17.

[8] Malviya, Amit, Dixit, Sanjay, Shukla, Harish, Mishra, Ankita, Jain, Abhineet and Tripathi, Amrita (2014). a study to evaluate internet addiction disorder among students of a medical college and associated hospital of central india, National Journal of Community Medicine, 5 (1), 93-95.

[9] Morahan-Martin J, Schumacher P. Incidence and correlates of pathological Internet use among college students. Comput Human Behav 2000; 16: 13-29

[10] Lam LT, Peng ZW, Mai JC, Jing J. Factors associated with Internet addiction among adolescents. Cyberpsychol Behav 2009; 12: 551-5.

[11] Warren, A., Brunner, D., Mair P., Barnet, L.,"Technology in Teaching and Learning: An Introductory Guide. London: Kogan Page, 1998

[12] Laurillard, D., "Learning through collaborative computer simulation", British Journal of Educational Technology, 23 (3), pp. 164-171, 1992

[13] Ciglaric, M., Vidmar, T., "The use of Internet technologies for teaching purposes", European Journal of Engineering Education, 23 (4), pp. 497-503, 1998.

[14] Charp, S., "The millennium classroom", T. H. E. Journal, 27 (10), pp. 10-12, 2000. 